Open Access

\title{
The use of wiki to promote students' learning in higher education (Degree in Pharmacy)
}

\author{
M. Encarnación Camacho*, M. Dora Carrión, Mariem Chayah and Joaquín M. Campos
}

\author{
* Correspondence: \\ ecamacho@ugr.es \\ Departamento de Química \\ Farmacéutica y Orgánica, Facultad \\ de Farmacia, Universidad de \\ Granada, 18071 Granada, Spain
}

\begin{abstract}
Nowadays, the expansion of new technologies in developed countries requires their inclusion in the higher educational systems, focused on the development of new skills to promote a continuous and independent learning process for the students. Internet technologies have reached a wide social diffusion, mainly among young people, and therefore the use of digital technologies at university, from smartphone apps to online collaboration tools, is becoming more and more embedded. This article describes the exploration of using wiki to promote the study of a degree in Pharmacy, particularly in the area of Pharmaceutical and Organic Chemistry, by creating a collaborative network that encourages group interaction instead of individual achievement. Our initiative is aimed at developing a number of skills and abilities of students and improving their academic performance and their comprehensive training. This work has been carried out with students, who followed Pharmaceutical Chemistries I and II, compulsory courses of the degree in Pharmacy, and it has been extended to other compulsory (Organic Chemistry II) and optional courses (Advanced Chemistry of Drugs), for a total of 200 students. Students have worked in teams on topics related to the subjects above indicated and have used wiki to develop their work. Opinion polls have shown a degree of satisfaction between high and very high in their performance, highlighting the benefits of using wiki in learning.

Keywords: Students' learning, Wiki, Collaborative network, University education, Web 2.0
\end{abstract}

\section{Introduction}

The use of technological tools on learning, such as online collaboration tools, presentation software or online course materials, has achieved widespread social dissemination (Tapscott, 2009), especially among young people, inviting the search for possibilities to improve teaching and to achieve the proposed educational objectives. The update on the university education system, due to the adaptation to the European Higher Education Area (EHEA), implies new demands on teachers (Curaj, Matei, Pricopie, Salmi, \& Scott, 2015). The creation of this area poses significant challenges, mainly derived from the change in the approach to the educational process. It has passed from teaching based on the transmission of knowledge and configured around the professor to a student-centered system, and to develop skills which enable them to perform their future professional work in the most appropriate way, as well as to facilitate their integration into the labor market system (Pérez Ríos, 2003).

(c) 2016 The Author(s). Open Access This article is distributed under the terms of the Creative Commons Attribution 4.0 International License (http://creativecommons.org/licenses/by/4.0/), which permits unrestricted use, distribution, and reproduction in any medium provided you give appropriate credit to the original author(s) and the source, provide a link to the Creative Commons license, and indicate if changes were made. 
We are now in a situation where the educational request is demanding and diverse, so it has been necessary to incorporate technologies for learning into teaching. This is what is known as e-Learning (Bichsel, 2013; Rosenberg, 2001). The development in recent years of new trends on the Internet, together with the concept of Web 2.0, has given rise to the need to move their application to education with the confidence that their characteristics contribute to achieve some of the goals set by the new system (Boza, 2009; Moreno, 2011). By using these new technologies (blogs, wikis, social networks, etc.), users do not behave as passive users only receiving the information, but they go on to become active members participating and contributing to edit that information.

In the last decades, emerging technologies, as this case work, have been introduced to both traditional classrooms and online courses, increasing motivation and facilitating the interchange of knowledge and expertise among students (Wankel, Marovich, \& Stanaittyte, 2010).

Wiki is a tool that can facilitate social interaction and collaboration, and this technology can be used to create a student-centered collaborative learning environment (Ruth \& Houghton, 2009; Augar, Raitman, \& Zhou, 2004; Hu \& Johnston, 1990). In this way, wiki is a website where a group of users can create, write, delete or change the content of a web page by easy and rapid interactivity. Wiki can also facilitate collective and constant review and the possibility of periodically extending the content and activities, essential in a learning process (Lipponen, 2002).

The use of such technologies is significant in teaching different subjects of the Degree in Pharmacy, such as Organic Chemistry and Pharmaceutical Chemistry. On the other hand, classes usually have a large number of students making it difficult to ensure effective verification of their work.

In this sense, this paper describes our experience and research based on the use of a wiki to help better understand the contents of these subjects. This Wiki could ease the exchange of ideas, motivate the students and promote their interest in the subject as well as facilitate the review of the students work by the instructor.

\section{Method}

This initiative was developed over two academic years and carried out in different subjects of the Degree in Pharmacy. This involved Organic Chemistry II (second year), Pharmaceutical Chemistry I (third year), Pharmaceutical Chemistry II (fourth year) and Advanced Chemistry of Drugs (fifth year), a total of 200 students. Students, whose participation in the use of a wiki was optional, have worked in groups of 2-3 people, on topics related to the subject and have used a wiki to develop their works. For example, they had to explain and review a scientific article related to a particular topic, or had to solve a synthetic route of different compounds with therapeutic activity based on knowledge of organic chemistry. Then, they had to expose their work done.

The following process took place:

1. Informational meetings about the use of wiki in university teaching, so that students know clearly the tool that will be used to share their knowledge within different subjects of Pharmaceutical and Organic Chemistry. 
2. Making a private wiki for collective learning in "wikispaces.com" by the administrator (teacher), and including students of the different subjects as group members.

3. Offering students topics and scientific articles related to the subjects to perform their works in group through wiki, to promote teamwork and collective intelligence. This aims to help students to understand better and assimilate the bases and contents. Students would work in each topic using wiki, sharing information with their peers through it, making their tasks and modifying in real time their work without the need of a physical meeting.

4. Oral presentation of the work done through wiki, aimed at helping students to gain a better understanding of the theoretical contents of the different subjects.

5. Self assessment by opinion polls of both the acceptance and the impact that this wiki has had on students who have used it.

The opinion poll data was collected as a survey and consisted of 17 questions split into four sections (see Figs. 1, 2, 3 and 4). In the first two sections, students marked their perception on four levels (low, medium, high and very high). The first section consisted of eight questions aimed to quantify the usefulness of the Wiki and its relevance in the learning process (Fig. 1): The Wiki tool is useful?; it promotes and increases the team work?; it promotes the active participation?; it improves the acquisition of concepts?; it is easy to use and to add contents to it?; it improves the expansion of knowledge?; it is useful in other degrees?; it is useful in other subjects?

The second section (Fig. 2) included four issues about the results achieved after using this tool. It seeks to check if the set time is enough to carry out the work, if the wiki really enable more contact with the teacher and colleagues or it helps the students to improve other skills. In these two sections, to answer the questions, participants had to choose one of four grades: low, intermediate, high and very high.

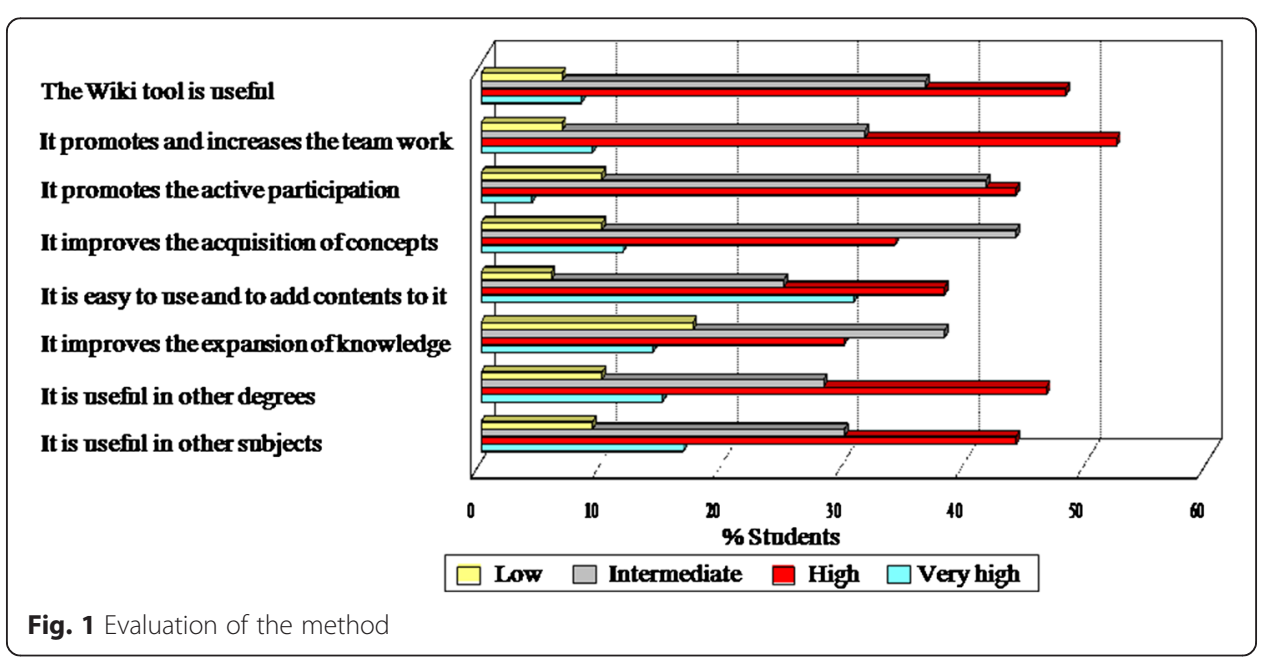




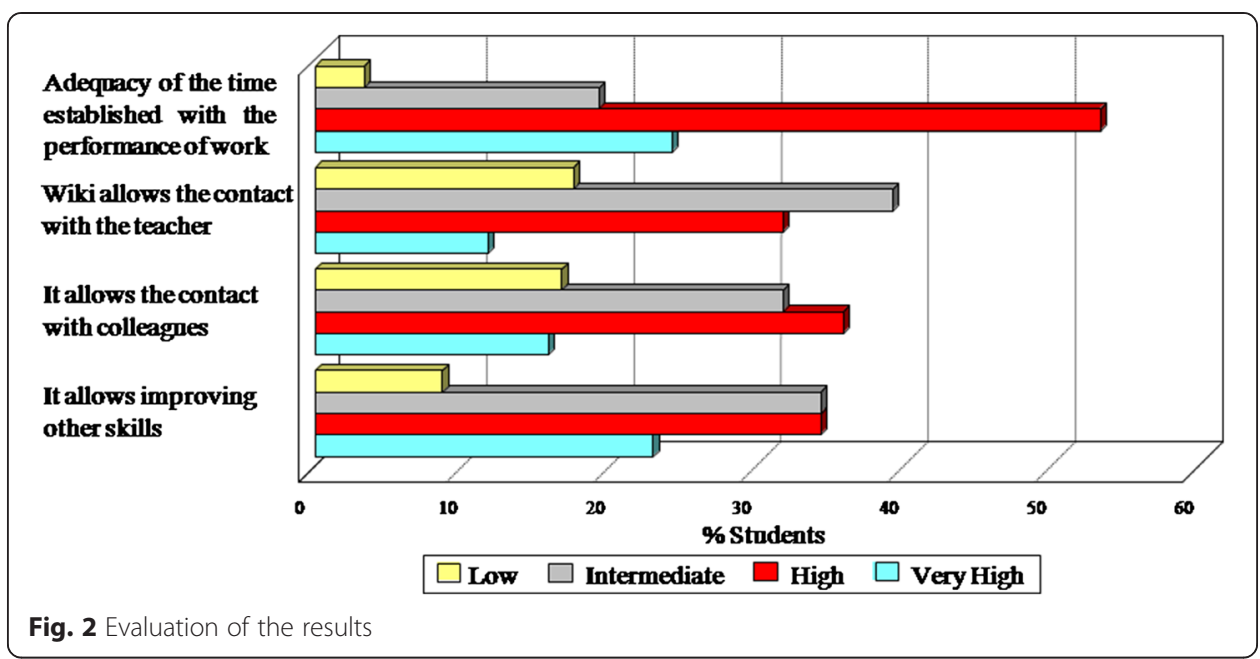

In the third section (Fig. 3), and through three questions, students were asked if they previously used the Wiki, also about the improvements they consider appropriate to perfect the wiki and its possible utility in the future.

Finally, the fourth part of the questionnaire was evaluated by the students also with four levels (low, intermediate, high and very high) to find out their overall rating (Fig. 4), regarding the initiative of using wiki and their involvement in this experience.

The questionnaires were collected at the end of the term. Once the survey data were gathered, all analysis was conducted with the SPSS version 15.0. Graphs were carried out to illustrate the results obtained.

The purpose of this initiative is to develop a range of skills and abilities in students to enhance their interest for the subjects by promoting group interaction instead of individual achievements and motivating them in order to improve their academic performance and comprehensive training.

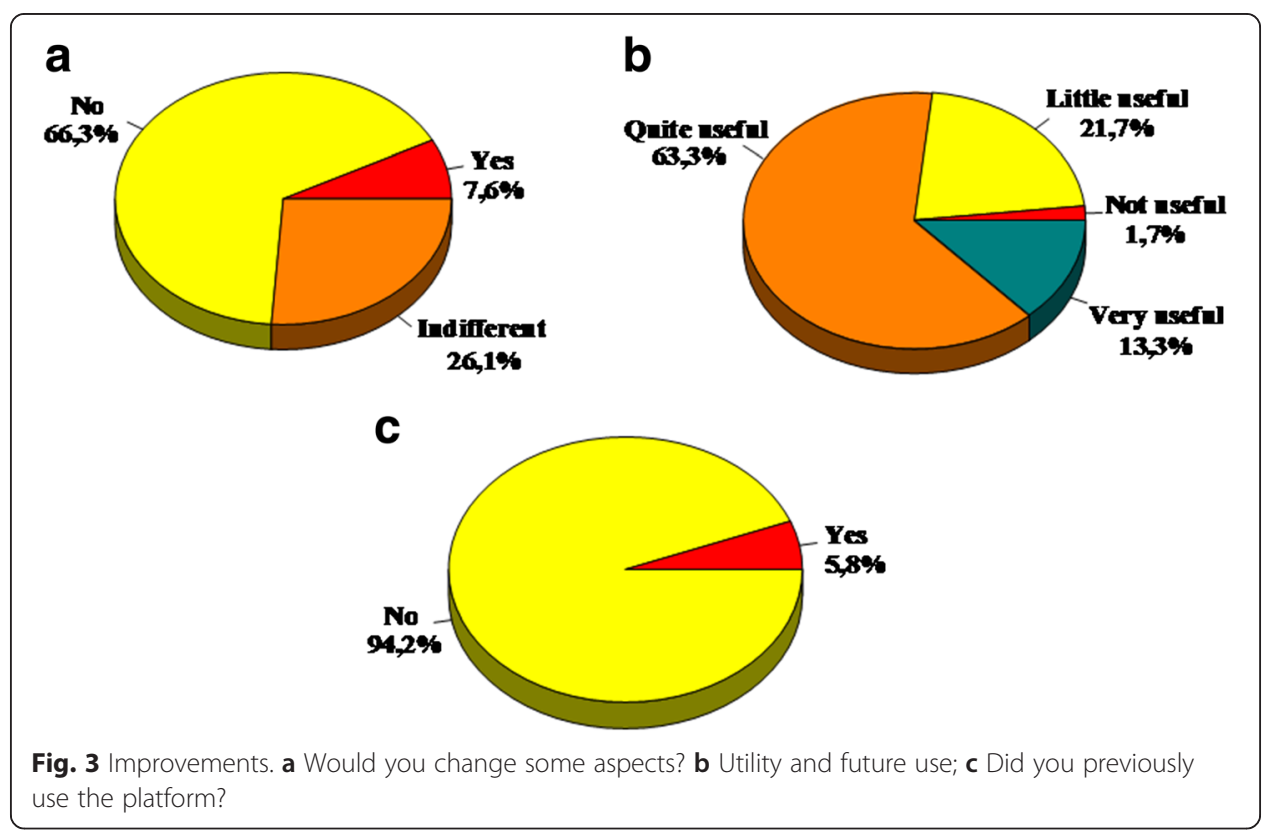




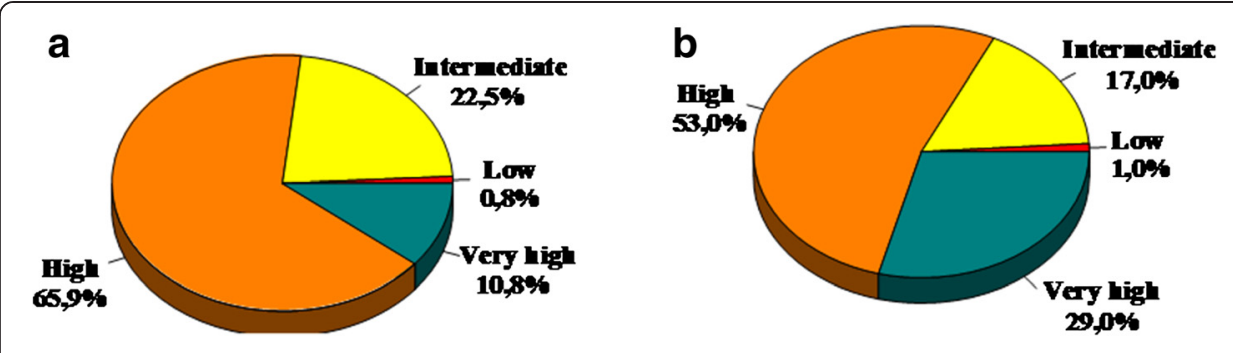

Fig. 4 Overall assessment: a Rating initiative; b Marking the involvement

\section{Results}

Internal evaluation and instruments

The assessment of this experience was made to the students who participated as volunteers by opinion polls. The results are discussed in the following four areas and are showed in Figs. 1, 2, 3 and 4.

\section{Students opinion on the usefulness of the Wiki}

Regarding the usefulness of Wiki in the teaching process, $37 \%$ of the participants qualify it as intermediate and $48 \%$ as high. This data indicates a wide acceptance of the method and implicitly an additional positive contribution that could be reflected in different levels. Thus, $52 \%$ of users think that the use of this tool promotes and encourages the teamwork since the work was carried out in groups without the need to be physically. Furthermore, the majority of students consider that they have acquired greater relevance and role in the learning process with their own contributions, contents and active participation (Fig. 1). Also they believe that the knowledge acquired through the teamwork development could not be learned in the normal course of the subject since only $8 \%$ indicates otherwise.

Respect to the handling of the Wiki, the vast majority believes that this tool is easy to use and to add contents to it (25\% intermediate, $38 \%$ high, and $31 \%$ very high) which was reflected in the fluency work and the few technical difficulties. $30 \%$ and $14 \%$ of students chose the high and very high option to indicate that the Wiki enables the expansion of the knowledge, discovering other aspects of the subjects like the research field and, not limited to the basic knowledge given in class. Finally, a very high percentage of the participants recommends the use of this method in other subjects of the Degree in Pharmacy and even incorporate it into more degrees.

\section{Student opinion on the communication and value of the Wiki}

Seventy-seven percent of students think that the time to carry out the work has been adequate (53\% high and $24 \%$ very high). In the set time, students had to read, understand, discuss and point their observations, opinions and reviews about scientific papers and works proposed by the instructor. Then, they had to prepare an oral presentation on the topic. In addition, a great number of students states that Wiki enables more contact with their teacher and classmates due to the discussions generated about the topics covered, which improves relationships between peers and provides a good study environment (Fig. 2).

Moreover, almost $60 \%$ of students (between high and very high options) consider that the use of Wiki and the oral presentation of work done contributed to improve 
other skills, among which the enhanced use of tools, learning the use of the page, managing specific programs for organic synthesis, or understanding some synthetic mechanisms in order to better assimilate the subject.

\section{Student opinion on how the use of the Wiki could be improved}

Students consider adequate the use of Wiki since only $8 \%$ of them would change some aspect in the development of the work done such as for example, to have more time for the preparation and presentation of work, while $66 \%$ believe they would not change any aspect, and $26 \%$ are indifferent (Fig. 3a). Besides, $76 \%$ of participants think that Wiki is useful to be reused in the future (13\% very useful and $63 \%$ quite useful), others believe that their usefulness is limited (22\%) or not useful (2\%) (Fig. 3b). Finally, most of them say they have not used this platform previously (94\%), and only $6 \%$ have used it ever (Fig. 3c).

\section{Overall assessment}

In general, the score of this initiative was quite satisfactory since only $1 \%$ of the students who have participated gave a low score, while most users qualify as high $(66 \%)$ or very high (11\%), both the tool itself and the acquisition of knowledge through it (Fig. 4a).

As for involvement in this experience, $82 \%$ gives a high and very high score, and only $17 \%$ an intermediate one (Fig. 4b), indicating that Wiki environment has been well accepted by students being useful to improve their learning process.

\section{Evaluation of student learning}

The evidences discussed in this section regarding student learning are based on the observation of lecturers and their personal appreciation of the evolution after using the Wiki in teaching. They suggest: Firstly, an increase of the users' motivation by issues related to Pharmaceutical and Organic Chemistries, resulting in a greater understanding of the theoretical contents reflected in improved exams marks. In addition, students increased their relationship with their teachers, as they need to solve questions related to the use of this tool in the work performance. Furthermore, an improved relationship among students has been noticed, as they should develop their work and solve problems together, agreeing on how to synthesize and transfer the work into the offered literature.

On the other hand, students have improved collectively their capacity of understanding, synthesis and presentation of the results. Also, an increase of students' interest in the work performance by using these new tools applied to teaching has been perceived. In addition, their critical capacity to be able to conduct the review and correction of issues uploaded to the platform by peers has been enhanced. Finally, an increase in the discussion, debate and communication between students has been observed along with the ability to take decisions together.

\section{Discussion}

This project has created a collaborative work platform on the web, which allows both teacher and students, to work together, which has promoted the collective intelligence and the exchange of ideas with improvement in the teacher-student relationship. In this way, an alternative learning method has been developed that allows a better integration of lessons, seminars and performance of works proposed by the teacher. In addition, as have been illustrated in the survey results, this initiative has led to a greater motivation 
of students for the acquisition of knowledge by using simple methodologies, and their critical capacity has been promoted, reflected in a better academic performance.

In general, both the implementation and the development of the project have been very positive, achieving all the initial objectives as demonstrated by the results of the opinion polls. In particular, among the improvements obtained after implementation of this scheme we can include:

- The ability to work independently, remote (on-line), at any time, from different computers without any meeting.

- Increasing interaction, not only between partners of the same group but also among colleagues from different groups.

- The encouragement of the student participation closer to the teacher.

- Learning to use a new platform and accommodating the use of this new intuitive technology.

- The ability to know the development of the work and changes made by peers.

- Learning to better expose in public.

- Increasing interest in the subject and knowing concepts that are not taught in class.

Its weaknesses include:

- The use of a new tool unknown for most of the student.

- The difficulty of understanding scientific texts in English, which sometimes affects the well development of the work.

\section{Conclusions}

In summary, a new tool has been learnt by students that can be useful for them in the future. They have increased their knowledge beyond the theoretical programme of the subjects, enhancing their academic yield. This method has improved collective and constant review by teachers and students. The performance of tasks has helped to understand better the theoretical contents of Pharmaceutical and Organic Chemistries as well as other skills related to it, such as the ability to synthesize and to expose in public. Wiki' flexibility and simplicity have been demonstrated as a platform that helps to improve student learning and to increase the diversity of perspectives while maintaining quality. The use of Wiki platform encourages students to learn about collaborative processes and fosters a sense of community, instead of an individual achievement as in a traditional competitive assessment.

Finally, opinion polls have shown a degree of satisfaction between high and very high on their performance, highlighting the benefits of using Wiki in the learning process.

Competing interests

The authors declare that they have no competing interests.

M. Encarnación Camacho is graduated in Pharmacy at the University of Granada (Spain). Associated Professor at the Faculty of Pharmacy in the area of Medicinal Chemistry. Co-author of three teaching books, a book chapter and five educational research articles. She has supervised four Doctoral Theses. Active participation in seven educational innovation projects, different tutorial innovation projects aimed at the development of tutorial action plans for students in the Faculty of Pharmacy, University of Granada, eight papers at international conferences aimed at university teaching in the last five year. Participation in several national and international conferences related to teacher training of university teachers in the EHEA field and several courses related to the educational teaching quality. 
M. Dora Carrión is graduated in Pharmacy at the University of Granada (Spain). Associated Professor at the Faculty of Pharmacy in the area of Medicinal Chemistry. She has supervised a Doctoral Thesis and has five educational research article. Active participation in six educational innovation projects, different tutorial innovation projects aimed at the development of tutorial action plans for students in the Faculty of Pharmacy, University of Granada. Eight papers at international conferences aimed at university teaching in the last five year. Participation in several courses and international congress related to the educational teaching quality. Currently, she is Erasmus Coordinator with various Italian universities.

Mariem Chayah is graduated in Pharmacy at the University of Granada (Spain). Doctor in Chemistry by University of Granada. Co-author of two educational research articles. Active participation in three educational innovation projects, three papers at international conferences aimed at university teaching. Participation in several courses related to the educational teaching quality.

Joaquín M. Campos is full Professor in Medicinal and Organic Chemistry. 5 books and 14 book chapters, and has supervised 13 Doctoral Theses. He is currently teaching Medicinal Chemistry at the Faculty of Pharmacy of Granada (Spain). He has imparted 8 courses on "Drug Design and Organic Syntheses" at the University of São Paulo, campus of RibeirãoPreto (Post-graduated programme in Pharmaceutical Sciences in the years 2004, 2006, 2008, 2011,2012 and 2014) and at the São Paulo campus (Post-graduated programme in Pharmaceutical Sciences in the years 2012 and 2015). Moreover, through these collaborations, professor Campos has contributed to improve the scientific and academic background of many former Brazilian students, who are now associate professors in several Brazilian universities. He received the Teaching Excellence Award 2010 from the University of Granada, within the category of teachers with over twenty-five years of teaching. He is representative of the University of Granada on the initiative Euro-PhD in Medicinal Chemistry (MedChem Euro-PhD) directed towards the international education of PhD medicinal chemistry students (01/01/2010-present).

\section{Acknowledgements}

The authors gratefully acknowledged to the Unity of Quality, Innovation and Prospective (University of Granada) the concession of teaching innovation project "Using wikis to foster student learning degree in Pharmacy".

Published online: 22 June 2016

\section{References}

Augar, N, Raitman, R \& Zhou, W. (2004).Teaching and learning online with Wikis. Proceedings of the 21st ASCILITE Conference: Beyond the comfort zone (95-104). Perth, Australia (December 5-8).

Bichsel, J. (2013).The state of e-learning in higher education: An eye toward growth and increased access. Louisville, EDUCASE Center for Analysis and Research.

Boza, A. (2009). Educación, investigación y desarrollo social. Madrid: NARCEA.

Curaj, A, Matei, L, Pricopie, R, Salmi, J \& Scott, P. (Eds.). (2015). The European Higher Education Area: Between Critical Reflections and Future Policies. Cham Heidelberg New York Dordercht London, Springer.

$\mathrm{Hu}, \mathrm{Q}$, \& Johnston, E. (1990). Using a Wiki-based course design to create a student-centered learning environment: Strategies and lessons. Journal of Public Affairs Education, 18(3), 493-512.

Lipponen, L. (2002). Exploring foundations for computer-supported collaborative learning. In G. Stahl (Ed.), Computer Support for Collaborative Learning: Foundations for a CSCL community. Proceedings of the Computer-supported Collaborative Learning 2002 Conference (pp. 72-81). Hillsdale: Erlbaum.

Moreno, T. (2011). Didáctica de la Educación Superior: nuevos desafíos en el s. XXI. Didactics Higher Education: New Challenges in the XXI century. Perspectiva Educacional, 50(2), 26-54.

Pérez Ríos, J. (2003). ¿Cómo usa el profesorado las nuevas tecnologías? Granada: Universitaria.

Rosenberg, MJ. (2001). E-learning strategies for delivering knowledge in the digitalage. Columbus USA, McGraw-Hill. Ruth, A, \& Houghton, L. (2009). The Wiki way of learning. Australasian Journal of Educational Technology, 25(2), 135-152. Tapscott, D. (2009). Grown Up Digital: How the Net Generation is Changing you World HC. McGraw-Hill.

Wankel, C, Marovich, M, \& Stanaittyte, J. (Eds.). (2010). Cutting-edge social media approaches to business education: Teaching with Linkedln, Facebook, Twitter, Second Life, and blogs. Scottsdale: IAP-Information Age Publishing, Inc.

\section{Submit your manuscript to a SpringerOpen ${ }^{\circ}$ journal and benefit from:}

- Convenient online submission

- Rigorous peer review

- Immediate publication on acceptance

- Open access: articles freely available online

- High visibility within the field

- Retaining the copyright to your article

Submit your next manuscript at $>$ springeropen.com 